\title{
SCIDiC
}

International Journal of Dentistry and Oral Science (IJDOS)

ISSN: 2377-8075

\section{Do Conservative Access Cavity Designs Increase The Etiological Complications Incidence Rate? (in Vitro Study)}

Research Article

Hussam Zaitoun ${ }^{1 *}$, Mouhammad Al Tayyan²

${ }^{1}$ MSc Student, Faculty of Dentistry, Department of Operative and Endodontics Dentistry, Damascus University, Syria.

${ }^{2}$ Professor, Faculty of Dentistry, Department of Operative and Endodontics Dentistry, Damascus University, Syria and DDS, PhD, Manchester University, UK.

\section{Abstract}

Introduction \& Aim: The aim of this study was to evaluate the effect of two conservative access cavity designs on etiological complications of root canal treatment for molar with severe root canal curvature (according to Schneider's classification). And comparing these differentdesigns to traditional endodontic access cavity.

Materials \& Methods: Thirty human intact freshly extractedmaxillary and mandibular molars with completely formed apices were used and then randomly divided into three groups. Group A (TEC) was accessed as (Traditional Endodontic Access Cavity) design completely following the principles of conventional endodontic access design that have well described in the literature. Group B (CEC) was accessed as (Conservative Endodontic Access Cavity) design described by David Clark \& John Khademi. Group C (Ultra-CEC) was accessed as small as possible and called an (Ultra-Conservative Endodontic Access Cavity) design and also known as "Ninja or Pointed" access. All stages were performed by the same operator and the same manual k-File \#8 \#10 and rotary files type, Pro-Glider, WOG-Primary for all groups. All steps were performed under microscope magnification.

Results: There was no statistical significant deference between groups for (handling glide path canal, ledges, perforations or separating instrument) by using Chi-Square Test for the triple compared among the groups and Fisher's Exact Test for the dual comparisons $(\mathrm{P}>0.05)$.

However, the third group Ultra-CEC showed statistical significant possibility for incidence etiological complications in total more than TEC, CEC Groups ( $\mathrm{p}<0.014)$.

Conclusions: CEC access cavity is a reasonable way to be less invasive than TEC in preparing endodontic access cavity without increasing incidence rate an etiological complication which may affect the biological aims of RCT. Ultra-CEC is a short way to make RCT more complicated and more likely to increase incidence rate of etiological complications.

Keywords: Conservative; Ultra-Conservative; Traditional Endodontic Access Cavity; "Ninja"; Etiological Complication; Minimally Invasive Dentistry.

\section{Introduction}

The aim of Endodontic treatments is to preserve the function of teeth and thepatient's health and periodontal tissues. But to achieve these goals, organisms in root canal system should be eliminated by well cleaning and shaping and sufficient irrigation to get high quality of sealing and obturation.[1]

Access cavity preparation is the foremost procedural step and one of the most important steps for successful endodontic treatment. [2]

The Traditional Endodontic Access Cavity (TEC) has been utilized for many decades as a gold standard for preparing access cavity in order to optimize the biological goals of endodontic treatmentby achieving sufficient entrance to root canal. In addition, an uncomfortable access might lead to etiological complications [3-5].

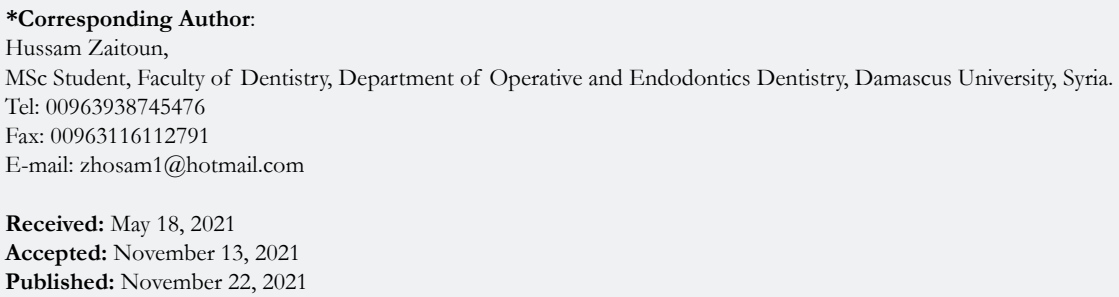

Copyright: Hussam Zaitoun ${ }^{\circ}$ 2021. This is an open-access article distributed under the terms of the Creative Commons Attribution License, which permits unrestricted use, distribution and reproduction in any medium, provided the original author and source are credited. 
However, the removal of tooth structure is required for access cavity preparation which may undermine the tooth strength to fracture under functional loads $[6,7]$.

Extraction is the most frequent consequence of fractured endodontically treated teeth (ETT) $[8,9]$. Extended preparation of endodontic access cavities critically reduces the amount of sound dentin $[10,11]$ and increases the deformability of the tooth [12], compromising the fracture strength of ETT.[10]

There are many developments in the field of dentistry including new instruments design, irrigation systems and tips, utilizing advanced imaging modalities and computer software and improving the accuracy of techniques; employing increased magnification and lighting for visualizing the pulpal space.[13] Because of these developments, new designs for conservative endodontic accesscavity designs have been advocated in order to minimize tooth structure removal.[14]

The approach of conservative endodontic access cavity (CEC) preparation aims to minimize tooth structure removal and preserve some of the chamber roof and pericervical dentin was reported in literature $[14,15]$. This sound dentin preservation could be achieved with the help of cone-beam computed tomographic (CBCT) imaging to identify all the canals $[16,17]$.

Following this concept, an extreme conservative approach has recently been proposed, which is conventionally known as "ninja" 42 .

Many studies showed a noticed higher fracture strength of conservative patterns of access cavity preparation [18, 19].

To date, according to author knowledge there aren't enough studies about the effect of these conservative approaches about increasing the risk of iatrogenic complication incidence. Therefore, this study investigates the potential riskof depending on these conservative paradigms in access cavity in severe curvature root molars.

\section{Materials and Methods}

Specimen selection and preparation: After ethics approval, thirtyfreshly extracted intact human maxillary and mandibular molars from Syrian population with completely formed apices and classified as severe curvature root canal according to Schneider's classification [21].

Exclusion criteria are the presence of caries or restorations could effect on the access cavity designs, and any molar which has root canal deformation, $j$ shape canals, coronal root curvature, $S$ shape canals, or molars that have nosevere curvature.

The specimen was cleansing with rubber cup and restored with $0.1 \%$ thymol solution until used in this study and between experimental phases to prevent dehydration [22]. Every molar was merged in heated flowing wax and then was merged in an acrylic mold to facilitate dealing with molar for take photos, radial images, and do endo-treatment.
The molars were distributed into 3 groups by using the website https://www.random.org for randomization, the upper and mandible molars randomized separately. Every group had 3 upper molars and 7 mandibular molars $(n=10)$. The radial scanning CBCT done by (PaX-i3D Green - @VatechGyeonggi-do, 445170 , South Korea) for planning the designs of access cavities of groups.http://www.vatech.com.

\section{Study Groups}

Group A: Traditional Endodontic Access Cavity TEC (Control Group).

Group B: Conservative Endodontic Access Cavity CEC. Group C: Ultraconservative Endodontic Access Cavity UltraCEC.

TEC: It's a geometrically predesigned shapes 10 . This access cavity design performed the straight access line to primary curved of canal or apical foramen and full removal of pulp roof and the walls of access cavity is perpendicular to the pulp floor and occlusal surface. (shape1)

CEC group molars were prepared following the recommendation of Clark \& Khademi [14, 15], the orifices in the same visual site could be approximately seen, and the outline enamel beveled at $45^{\circ}$, without paying attention to the principles of TEC; deroofing and getting straight access line to the primary apical curvature. (shape1)

Ultra-CEC group molars were prepared following the rule of getting an access from a central fossa to all orifices and the pulpal roof maintained as possible. The "Ninja" Ultra-CEC access derived from the oblique projection from every orifice to the central fossa, so only one orifice can be seen in the same time.42 (shape1)

Endodontic Treatment: Accesses of molars for all groupsTEC, CEC, and Ultra-CEC have drilled with Mani TR25 199/016 (Mani, Japan) mounted on a hand piece with water cooling19. And probed the orifices with DG16 Endo-prob (Dentaluck- Pakistan).

Root canals were negotiated with size \#8-\#10 K-type files (Mani,Inc. TOCHIGI, JAPAN) to the major apical foramen, and canals were instrumented to length with one glide path file (Proglider; DentsplyMaillefer, Ballaigues, Switzerland) and one shaping file (WOG; WaveOne Gold Primary; DentsplyMaillefer, Ballaigues, Switzerland).

The Files are replaced every 9 canals or when separation occurred, for each group separately. Irrigation has done with $\mathrm{NaOCl}$ $5.25 \%$ between phases, $2 \mathrm{ml}$ for every new file and every three biking motion. endoEze (Ultradent, USA) irrigation tips were used. All steps were done under microscope (Dental SEMORR Dom 3000-E microscope, China) and the treatment done by the same operator with five years of experience.

Recording the results: The canals which couldn't be scouted or negotiated by manual files, were recorded, and it's excluded from the later treatment steps.

By the complete treatment of canals with rotary files, it was recorded any iatrogenic complication happened like "Ledges, perfo- 
rations, separated instruments".

Statistical Analysis: The software SPSS version 24 was used to perform the statistical analysis. Thus, the results were statistically evaluated using analysis of Chi Square test for multiple comparisons and Fisher's Exact Test for dual comparisons studying iatrogenic complication.

Significance level established at 5\% (P<0.05).

\section{Results}

Group C (Ultra-CEC) showed significant difference by having a higher iatrogenic complication incidence $(\mathrm{P}<0.05)$ more than other Groups TEC,CEC. There is no significant difference between TEC, CEC for increasing the risk of iatrogenic complications.

There aren't any significant differences among the groups by dual comparison or multiple comparison for each type of investigated iatrogenic complications $(\mathrm{P}>0.05)$.

\section{Discussion}

One of the most important causes of dental fractures is the loss of tooth structure. The preparation of endodontic access cavity following TEC principles was reported as the second largest cause of loss of tooth structure [23]. Thus, a proper and contracted endodontic access design could improve the prognosis for ETT [24].

Many studies of finite elements analysis showed that the loss of tooth structure has the most important reason of tooth fracture. And the cervical strains increased by increasing the taper of preparing coronal canal space [25-27].

Recently, CEC and Ultra-CEC were proposed to reduce the fracture risk in ETT [18].

It is deemed that all subsequent steps which follow endodontic cavity preparation may be compromised if adequate access is lacking. An endodontic cavity that has been inadequately prepared will make the locating, negotiating, debriding, disinfecting, and filling of the root canal system a challenging tasks. An adequate endodontic cavity also aids in preventing iatrogenic complications during endodontic treatment procedures. Any of the above complications may contribute to reduce prognosis of endodontic therapy. [2-4, 28].

Recently many studies have been done to investigate the benefit of CEC, Ultra-CEC and Truss access in many teeth types for increasing dental structure strength to occlusal forces. And others investigating the influence of contracted designs on root canal

Shape1. Photographs clarify the deference among the three study groups in endodontic access designs for both upper and mandible molars for each group.

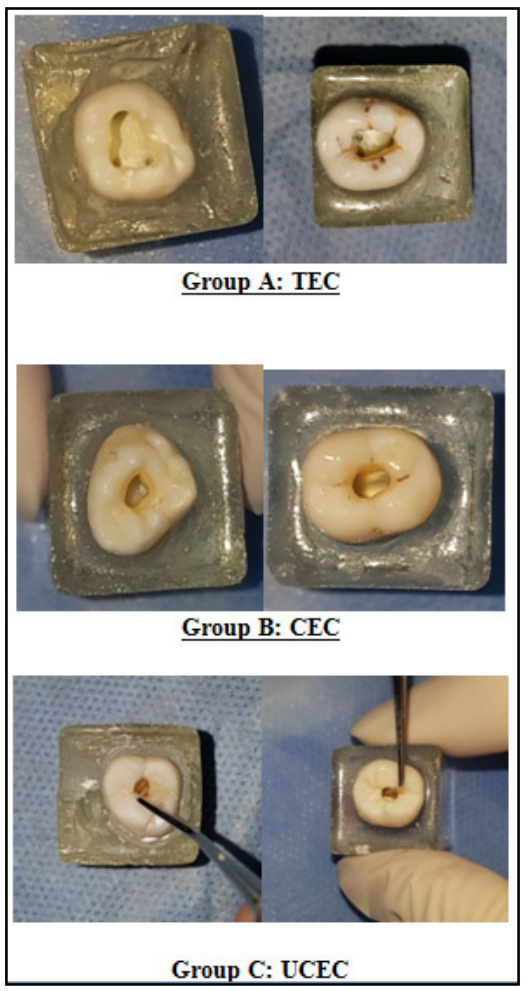

Figure 2 .

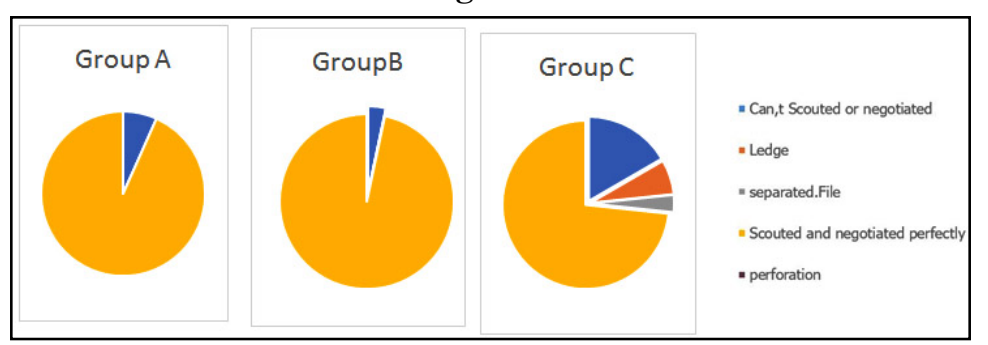


geometry, disinfection, shaping efficacy and influence on root canal detection. But the results still compromised [2, 18, 19, 22, 29, $40]$ and this is possibly because there were no determined developed protocols for minimally invasive endodontic, and many differences found in methodology of accessing the cavity between studies in each type of conservative designs and methodology of applying experimental tests.

In this study all cases chosen from the severely curved canals according to Schneider's classification because the fact of; the more curved canal the more complications will happen. And some curves don't appear on the periapical radiographs when it is in the buccal-lingual plane [41]. And the classification has been unified to eliminate the selective bias from this study.

CBCT has beendone to plan for access design and avoiding errors when preparing the access cavity.[19]

The same operator has performed all specimen preparation procedures in order to avoid the effects of the operator skills effect. [19]

Some authors pointed that although the CEC designs increase the tooth strength but it may increase the risks of inefficient canal instrumentation and the incidence of procedural errors $[18,19]$.

Depending on thermo-files treated system design may decrease the potentiality of causing iatrogenic complications like ledges and instruments separation because of high flexibility and have a good insufficient shaping and it has more resistance for cyclic fatigue.

Many studies pointed that no complications happened during treatment, but others excluded some specimens because of the occurrence of some errors without pointing to their nature. And all previous studies were trying to avoid falling in complications by the single use of rotary files per molar or per 4-5 canals in maximum. And there is an obvious difference between the degree of curved root among studies and what were chosen"severe degree curved canals".

Ultra-CEC showed significantlystatistical difference in increasing iatrogenic complications than TEC and CEC. This can be illustrated because of the coronal obstructions which put more stress on instruments and have a negative impact on handle sensation and operator control. Ultra-CEC design focused on preservation of occlusal access plane (the less important tissue) more than pericervical dentine (the more important tissue).

The term of conservative endodontic access is still a description terminology and it should be controlled by more precise criteria considering the effect on negotiation possibility, and quality of cleaning and shaping, irrigation and obturation. Depending on high quality modern systems in diagnosing, illumination, magnification, preparation, irrigation and obturation could improve our access cavity to be more conservative.

\section{Conclusion}

Within the limitations of this study, it can be concluded that depending on conservative designs should be judiciously assessed before being accepted into routine clinical practice, because of Ultra-CEC design increased the incidence of iatrogenic complications, and then would make treatment steps more complicated.

The CEC access cavity design seems morelikely acceptable design to be less invasive without increasing iatrogenic complications incidence rate.

\section{References}

[1]. Schilder H. Cleaning and shaping the root canal. Dent Clin North Am. 1974 Apr;18(2):269-96. PubMed PMID: 4522570.

[2]. Christie WH, Thompson GK. The importance of endodontic access in locating maxillary and mandibular molar canals. J Can Dent Assoc. 1994 Jun;60(6):527-32, 535-6. PubMed PMID: 8032994.

[3]. Ingle J, Beveridge E. Endodontics. 3rd. Philadelphia: Lea \&Febiger 1985:178-180.

[4]. Patel S, Rhodes J. A practical guide to endodontic access cavity preparation in molar teeth. Br Dent J. 2007 Aug 11;203(3):133-40. PubMed PMID: 17694021.

[5]. Ingle JI. endoonticcatity preparation. Endodntics. 1994:92-227.

[6]. Kishen A. Mechanisms and risk factors for fracture predilection in endodontically treated teeth. Endodontic topics. 2006;13(1):57-83.

[7]. Tang W, Wu Y, Smales RJ. Identifying and reducing risks for potential fractures in endodontically treated teeth. J Endod. 2010 Apr;36(4):609-17. PubMed PMID: 20307732.

[8]. Touré B, Faye B, Kane AW, Lo CM, Niang B, Boucher Y. Analysis of reasons for extraction of endodontically treated teeth: a prospective study. J Endod. 2011 Nov;37(11):1512-5. PubMed PMID: 22000453.

[9]. Vire DE. Failure of endodontically treated teeth: classification and evaluation. J Endod. 1991 Jul;17(7):338-42. PubMed PMID: 1779219.

[10]. Asundi A, Kishen A. Advanced digital photoelastic investigations on the tooth-bone interface. J Biomed Opt. 2001 Apr;6(2):224-30. PubMed PMID: 11375733.

[11]. Bassir MM, Labibzadeh A, Mollaverdi F. The effect of amount of lost tooth structure and restorative technique on fracture resistance of endodontically treated premolars.J Conserv Dent. 2013 Sep;16(5):413-7. PubMed PMID: 24082569.

[12]. Lang H, Korkmaz Y, Schneider K, Raab WH. Impact of endodontic treatments on the rigidity of the root. J Dent Res. 2006 Apr;85(4):364-8. PubMed PMID: 16567560.

[13]. Gluskin AH, Peters CI, Peters OA. Minimally invasive endodontics: challenging prevailing paradigms. Br Dent J. 2014 Mar;216(6):347-53. PubMed PMID: 24651341.

[14]. Clark D, Khademi J. Modern molar endodontic access and directed dentin conservation. Dent Clin North Am. 2010 Apr;54(2):249-73. PubMed PMID: 20433977.

[15]. Clark D, Khademi JA. Case studies in modern molar endodontic access and directed dentin conservation. Dent Clin North Am. 2010 Apr;54(2):27589. PubMed PMID: 20433978.

[16]. Patel S, Dawood A, Ford TP, Whaites E. The potential applications of cone beam computed tomography in the management of endodontic problems. IntEndod J. 2007 Oct;40(10):818-30. PubMed PMID: 17697108.

[17]. Horner K, O'Malley L, Taylor K, Glenny AM. Guidelines for clinical use of CBCT: a review. DentomaxillofacRadiol. 2015;44(1):20140225. PubMed PMID: 25270063.

[18]. Krishan R, Paqué F, Ossareh A, Kishen A, Dao T, Friedman S. Impacts of conservative endodontic cavity on root canal instrumentation efficacy and resistance to fracture assessed in incisors, premolars, and molars. J Endod. 2014 Aug;40(8):1160-6. PubMed PMID: 25069925.

[19]. Plotino G, Grande NM, Isufi A, Ioppolo P, Pedullà E, Bedini R, Gambarini G, Testarelli L. Fracture Strength of Endodontically Treated Teeth with Different Access Cavity Designs. J Endod. 2017 Jun;43(6):995-1000. PubMed PMID: 28416305.

[20]. Ericson D. The concept of minimally invasive dentistry. Dent Update. 2007 Jan-Feb;34(1):9-10, 12-4, 17-8. PubMed PMID: 17348554.

[21]. Balani P, Niazi F, Rashid H. A brief review of the methods used to determine the curvature of root canals. J Res Dent. 2015 Oct;3(3):57-63.

[22]. Moore B, Verdelis K, Kishen A, Dao T, Friedman S. Impacts of Contracted Endodontic Cavities on Instrumentation Efficacy and Biomechanical Responses in Maxillary Molars. J Endod. 2016 Dec;42(12):1779-1783. PubMed PMID: 27871481.

[23]. RezaeiDastjerdi M, Amirian Chaijan K, Tavanafar S. Fracture resistance of upper central incisors restored with different posts and cores. Restor Dent Endod. 2015 Aug;40(3):229-35. PubMed PMID: 26295027. 
[24]. Ikram OH, Patel S, Sauro S, Mannocci F. Micro-computed tomography of tooth tissue volume changes following endodontic procedures and post space preparation. IntEndod J. 2009 Dec;42(12):1071-6. PubMed PMID: 19912377.

[25]. Allen C, Meyer CA, Yoo E, Vargas JA, Liu Y, Jalali P. Stress distribution in a tooth treated through minimally invasive access compared to one treated through traditional access: A finite element analysis study. J Conserv Dent. 2018 Sep-Oct;21(5):505-509. PubMed PMID: 30294111

[26]. Zelic K, Vukicevic A, Jovicic G, Aleksandrovic S, Filipovic N, Djuric M. Mechanical weakening of devitalized teeth: three-dimensional Finite Element Analysis and prediction of tooth fracture. IntEndod J. 2015 Sep;48(9):85063. PubMed PMID: 25243348.

[27]. Zhang Y, Liu Y, She Y, Liang Y, Xu F, Fang C. The Effect of Endodontic Access Cavities on Fracture Resistance of First Maxillary Molar Using the Extended Finite Element Method.J Endod. 2019 Mar;45(3):316-321. PubMed PMID: 30803539.

[28]. Bóveda C, Kishen A. Contracted endodontic cavities: the foundation for less invasive alternatives in the management of apical periodontitis. Endodontic Topics. 2015 Nov;33(1):169-86

[29]. Abou-Elnaga MY, Alkhawas MAM, Kim HC, Refai AS. Effect of Truss Access and Artificial Truss Restoration on the Fracture Resistance of Endodontically Treated Mandibular First Molars.J Endod. 2019 Jun;45(6):813-817. PubMed PMID: 30905571.

[30]. Al Amri MD, Al-Johany S, Sherfudhin H, Al Shammari B, Al Mohefer S, Al Saloum M, Al Qarni H. Fracture resistance of endodontically treated mandibular first molars with conservative access cavity and different restorative techniques: An in vitro study. AustEndod J. 2016 Dec;42(3):124-131. PubMed PMID: 26992005.

[31]. Alovisi M, Pasqualini D, Musso E, Bobbio E, Giuliano C, Mancino D, Scotti N, Berutti E. Influence of Contracted Endodontic Access on Root Canal Geometry: An In Vitro Study. J Endod. 2018 Apr;44(4):614-620. PubMed PMID: 29336881.

[32]. Chlup Z, Žižka R, Kania J, Přibyl M. Fracture behaviour of teeth with conventional and mini-invasive access cavity designs. Journal of the European Ceramic Society. 2017;37(14):4423-4429.

[33]. Corsentino G, Pedullà E, Castelli L, Liguori M, Spicciarelli V, Martignoni M, Ferrari M, Grandini S. Influence of Access Cavity Preparation and Re- maining Tooth Substance on Fracture Strength of Endodontically Treated Teeth. J Endod. 2018 Sep;44(9):1416-1421. PubMed PMID: 30049468.

[34]. Ivanoff CS, Marchesan MA, Andonov B, et al. Fracture resistance of mandibular premolars with contracted or traditional endodontic access cavities and class II temporary composite restorations. Endodontic Practice Today. 2017;11:7-14.

[35]. Roperto R, Sousa YT, Dias T, Machado R, Perreira RD, Leoni GB, PalmaDibb RG, Rodrigues MP, Soares CJ, Teich S, Sousa-Neto MD. Biomechanical behavior of maxillary premolars with conservative and traditional endodontic cavities. Quintessence Int. 2019;50(5):350-356. PubMed PMID: 30957110 .

[36]. Rover G, Belladonna FG, Bortoluzzi EA, De-Deus G, Silva EJNL, Teixeira CS. Influence of Access Cavity Design on Root Canal Detection, Instrumentation Efficacy, and Fracture Resistance Assessed in Maxillary Molars. J Endod. 2017 Oct;43(10):1657-1662. PubMed PMID: 28739013.

[37]. Sabeti M, Kazem M, Dianat O, Bahrololumi N, Beglou A, Rahimipour K, Dehnavi F. Impact of Access Cavity Design and Root Canal Taper on Fracture Resistance of Endodontically Treated Teeth: An Ex Vivo Investigation. J Endod. 2018 Sep;44(9):1402-1406. PubMed PMID: 30049471.

[38]. Saygili G, Uysal B, Omar B, Ertas ET, Ertas H. Evaluation of relationship between endodontic access cavity types and secondary mesiobuccal canal detection. BMC Oral Health. 2018 Jul 6;18(1):121. PubMed PMID: 29980211

[39]. Silva EJNL, Rover G, Belladonna FG, De-Deus G, da Silveira Teixeira C, da Silva Fidalgo TK. Impact of contracted endodontic cavities on fracture resistance of endodontically treated teeth: a systematic review of in vitro studies. Clin Oral Investig. 2018 Jan;22(1):109-118. PubMed PMID: 29101548.

[40]. Vieira GCS, Pérez AR, Alves FRF, Provenzano JC, Mdala I, Siqueira JF Jr, Rôças IN. Impact of Contracted Endodontic Cavities on Root Canal Disinfection and Shaping. J Endod. 2020 May;46(5):655-661. PubMed PMID: 32201072.

[41]. Lin LM, Rosenberg PA, Lin J. Do procedural errors cause endodontic treatment failure? J Am Dent Assoc. 2005 Feb;136(2):187-93; quiz 231. PubMed PMID: 15782522

[42]. Belograd.M. The Genious 2 is coming. Available: ninja-access-a-new-accessconcept-in-endodontics 2016 [Accessed September 18]. 